\title{
Norbert Kroó
}

\section{INTRODUCTORY REMARKS}

The logo of the Institute of Advanced Studies Köszeg (iASK) refers to a more than 100 - year old, but still topical problem: how to join 9 dots arranged in a box - like square format with four straight lines without lifting the pen. The solution is only possible if, while moving the pen, we get out of the box. The box in fact does not exist, it is only a self imposed virtual limitation. Even more, the task can be solved also by using just one straight line, the only problem is that in order to achieve that the earth has to be circled twice. But why not circle the earth twice? We certainly have to consider the cost/benefit aspect as well but the lesson must not be forgotten: we shoud think twice before calling the solution of a task impossible.

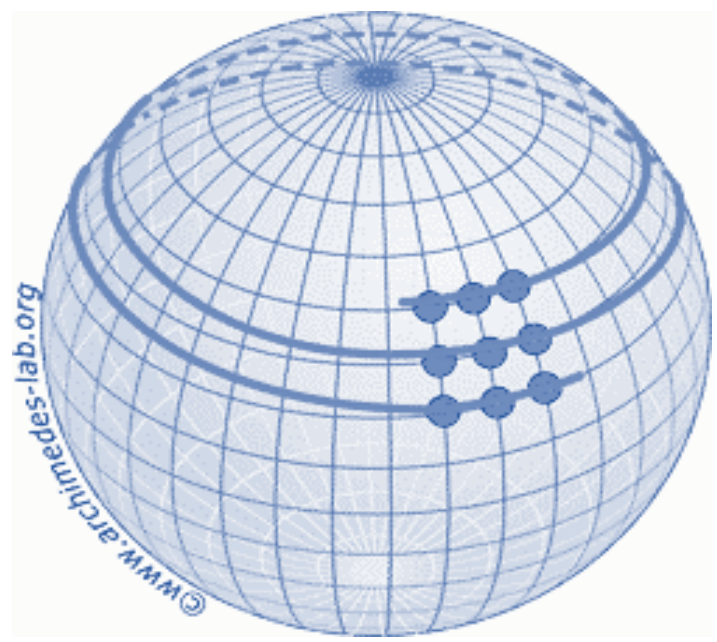

(https://www.artofplay.com/blogs/articles/history-of-the-nine-dot-problem)

This mentality characterizes the Institute of Advanced Studies Köszeg, that has been functioning since 2015. Its intellectual and organizational roots go back for about three decades to the Institute of Social and European Studies Foundation, that both in research and teaching also integrates theoretical and practical studies, responds rapidly to changing social and economic conditions, not only in teaching and scholarly publicatons, but also by working out policy proposals. Transferring up to date knowledge about topical issues to the non-academic society is also as

DOI: 10.14267/RETP2021.03.01 
important for the institute as high level research. According to the philosophy of the Institute traditional, greatly segmented research and educational structures do not reflect the complexity of problems in our age of uncertainties with increasing levels of threats. Therefore integrated, multidisciplinary approaches are believed to be the winners.

I have been working at the Hungarian Academy of Sciences and at numerous toplevel international institutions for more than sixty years and both as a physicist and as a leader of all types of research structures, I have learnt a lot about individual and institutional creativity. Scientific success is rooted in a never ending curiousity driven approach, expressed in clearly formulated questions and continous reflections on the local, regional and more global problemsin the world. As I have been following the making and working of the Institute and the Foundation from the very beginning, I could witness their implementation of these principles. The content of this issue of Köz-Gazdaság is a clear evidence for that. I warmly recommend its reading. 